\title{
Internal social capital and the life cycle of agricultural cooperatives
}

\author{
Wendong Deng ${ }^{1} \cdot$ George Hendrikse $^{2} \cdot$ Qiao Liang $^{3}$ \\ Published online: 27 June 2020 \\ (C) Springer-Verlag GmbH Germany, part of Springer Nature 2020
}

\begin{abstract}
This paper provides an integrated analysis of the structural, relational, and cognitive dimensions of social capital in cooperatives. The social capital concept is integrated with cooperative lifecycle theory to describe the change of cooperative social capital along the lifecycle. We propose that cooperatives in different stages of the lifecycle are featured with different levels of social capital. Cooperatives usually enjoy a high level of social capital in the early stages of the lifecycle. However, the level of social capital in cooperatives exhibits a declining trend along the development of the organization. The decrease of social capital will lead to an imbalance of the social and economic attributes of cooperatives. The cooperative's governance structure must change accordingly. We argue that it is important for cooperatives to maintain and develop the social capital strategically over time. Otherwise, the comparative advantage of the cooperative business form may disappear.
\end{abstract}

Keywords Social capital $\cdot$ Cooperatives $\cdot$ Lifecycle

JEL Classification D02 $\cdot \mathrm{L} 29 \cdot \mathrm{Q} 13$

Qiao Liang

liangqiao2323@126.com

Wendong Deng

wdeng@rsm.nl

George Hendrikse

ghendrikse@rsm.nl

1 China Academy for Rural Development, Zhejiang University, Hangzhou, China

2 Rotterdam School of Management, Erasmus University, Rotterdam, Netherlands

3 China Academy for Rural Development, School of Public Affairs, Zhejiang University,

Yuhangtang 866, Zhejiang 310058 Hangzhou, China 


\section{Introduction}

'A cooperative is a user-owned and user-controlled business from which benefits are derived and distributed on the basis of use' (Dunn 1988). Cooperatives of different types exist in various sectors, dependent on the identity of users. There are consumer, worker, producer, and credit cooperatives, etc. These cooperatives have different features, with some more economic-oriented while others more association like. We focus on farmer cooperatives, the members of which are farmers having an ownership and transaction relationship with the cooperative enterprise. Cooperatives play an important role in the agribusiness because they advance farmers' economic interests by bringing them the benefits such as economies of size, elimination of double marginalization, profits from processing, assurance of product outlet, gains from vertical and horizontal coordination, risk reduction, countervailing power, competitive yardstick effects, etc. (e.g. Cook 1995; Liang 2013). Cooperative researchers have investigated how cooperatives are distinct from other organizational forms in a broad range of themes (Hendrikse and Feng 2013). To address these topics, various theoretical perspectives are applied, including agency theory (e.g. Cook 1995; Hueth and Marcoul 2009), transaction costs theory (e.g. Bonus 1986; Hendrikse and Veerman 2001a), property rights theory (e.g. Fulton 1995; Hendrikse and Veerman 2001b), game theory (e.g. Hendrikse 1998), and bounded cognition theory (e.g. Feng 2011), etc. However, one common shortcoming of these theoretical approaches is that they largely ignore the embeddedness of the cooperative's and members' economic activities in the social context of the cooperative's community. The explanatory relevance of the social relationships among cooperative members is not taken into consideration.

It is commonly argued that social capital is a valuable asset based on inter-personal social relationships (e.g. Coleman 1990; Adler and Kwon 2002). Cooperatives are regarded as 'social capital-based organizations' (Valentinov 2004) or as 'dual organizations' (Nilsson and Hendrikse 2011). Therefore, social capital is potentially important in addressing the difference between cooperatives and investor owned firms (IOFs) because 'the existence of this social foundation of cooperation, giving rise to its expressly democratic and people-oriented character, was the basis for differentiating between the cooperative and "capitalistic" organization' (Valentinov 2004). Social capital has been recognized as a main comparative advantage of the cooperative form (Røkholt 1999; Spear 2000). In addition, cooperatives, compared to other enterprise forms, have a better ability to foster social capital (Sabatini 2014).

Social capital at the organizational level can be categorized as internal and external social capital (Adler and Kwon 2002; Leana and Pil 2006). ${ }^{1}$ Internal social capital describes the aggregate form and value of social relationships among organizational members (e.g. Coleman 1990; Putnam 1993), whereas external social capital describes the social linkages between the organization and other external actors (e.g. Burt 1992; Uzzi 1996). In this paper, we focus on the internal social capital of cooperatives. In other words, we treat a cooperative as a community and look at the structure and

\footnotetext{
${ }^{1}$ Social scientists have categorized the forms of social capital in other ways, such as bonding and bridging (e.g. Adler and Kwon 2002; De Carolis and Saparito 2006), or intra- and inter-organizational (e.g. Arregle et al. 2007). These characterizations of social capital are similar to the internal and external view adopted in the current study. See Payne et al. (2011) for a typology of social capital.
} 
content of relationships among its members, which facilitate the pursuit of collective goals of the cooperative (Adler and Kwon 2002). For the sake of simplicity, the term 'social capital' hereafter refers to the internal social capital and our discussion is geared to farmer cooperatives.

In the cooperative literature, many issues related to the notion of social capital, including ideology, culture, value, trust, identity, norms, loyalty and commitment, have been studied by scholars (e.g. Fulton and Adamowicz 1993; Hansen et al. 2002; Valentinov 2004; James Jr. and Sykuta 2006; Bhuyan 2007; Nilsson et al. 2012). In examining these studies, we find that an integrated analysis of social capital of cooperatives is missing. Therefore, the primary purpose of this paper is to conduct a literature review and develop a theoretical connection between social capital and cooperative organizations.

Accordingly, we strive to achieve three objectives in this paper. The first objective is to identify the content of social capital of cooperatives and the benefits resulting from it. To achieve this objective, we adopt Nahapiet and Ghoshal's (1998) three dimensions of social capital: structural, cognitive, and relational. From the perspective of a system of attributes (Milgrom and Roberts 1990), these social capital dimensions constitute the social attributes of the cooperative, which must be aligned with the cooperative's governance attributes. By reviewing both cooperative and social capital literature, we delineate each social capital dimension and discuss how they may generate comparative advantages for cooperatives.

Second, this paper integrates diverse ideas and empirical facts that pertain to cooperative social capital with cooperative lifecycle theory. Although social capital is an asset of traditional cooperatives, the level of social capital in a cooperative is by no means static. The development and expansion of the cooperative will change the environment where social capital develops and sustains. Some researchers attribute the failure of some large cooperatives to the decline of social capital in the organization (Nilsson et al. 2012). In addition, the role of social capital varies under different institutional contexts (Kraft and Brasch 2018). Based on Cook's (1995) cooperative lifecycle model, we describe the change of social capital along the cooperative lifecycle and its potential impacts on cooperatives' business performance. Our fundamental argument is that the social capital level in a cooperative may decrease along the cooperative lifecycle. The decrease of the level of social capital leads to an imbalance of the social and economic attributes of the cooperative. When this happens, the cooperative's governance structure may become inefficient and need to be changed.

Third, and finally, we argue that it is important that cooperative leaders strategically maintain and recover cooperative social capital over time. Otherwise, the comparative advantage of cooperatives over IOFs may disappear. We discuss the implications for the management practice in cooperatives. Specifically, we offer some suggestions to maintain and recover social capital in large and modern cooperatives.

Our research contributes to the literature by specifying the content of each social capital dimension of farmer cooperatives and how they may change along the cooperative life cycle. There is a sizable literature specifying the content of social capital, i.e., structural, cognitive, and relational, as well as their interactions in the social community and in general enterprises (e.g. Tsai and Ghoshal 1998; Leana and Pil 2006). Many cooperative scholars have emphasized the importance of social capital and tried to link it with the development and performance of cooperatives (e.g., Liang et al. 2015; 
Nilsson et al. 2012; Valentinov 2004). However, owing to the multi-dimensionality of the social capital concept, previous research usually focuses on specific facets or components of social capital and uses various constructs to measure it. We are the first to provide an analytical frame for the content and benefit of each dimension of internal social capital of farmer cooperatives, based on an extensive review of the literature.

In the literature on organization life cycle, the changes of various features, e.g. governance structure and management strategies, with the organization life cycle are investigated (Smith et al. 1985; Lester et al. 2003). Some researchers demonstrate the decline of social capital, which is mostly reduced to one dimension such as trust, as organization size and complexity of cooperatives increase (Feng et al. 2016; Nilsson et al. 2012). However, a comprehensive analysis regarding the change of social capital along the whole life cycle of cooperatives, to the best of our knowledge, is not done.

The managerial contribution of the current paper lies in cooperative managers having a better understanding of social capital in cooperatives and target at specific dimensions of social capital to enhance coordination efficiency. Although it may be beneficial to invest in all dimensions of social capital, it is costly to build and maintain social capital (Mors 2010; Kraft and Brasch 2018). It is, therefore, relevant that managers have knowledge regarding the specific stage that cooperatives are experiencing and the features of social capital at that stage.

This paper is organized as follows. In Section 2, we develop an integrated analysis of cooperative social capital. Section 3 contours the evolution of cooperative social capital along the lifecycle with illustrative empirical evidence. In Section 4, we discuss the practical implications of social capital for the management of cooperatives. The last section encompasses conclusions and presents some implications for future research on cooperative social capital.

\section{Social capital and cooperatives}

According to Nahapiet and Ghoshal (1998), social capital is composed of three distinct dimensions: structural, cognitive and relational. The measurement of social capital can be operationalized according to these dimensions (e.g. Tsai and Ghoshal 1998; Leana and Pil 2006; Wu 2008). In the following subsections, each dimension will be examined in the organizational setting of cooperatives. Our analysis aims at laying the ground work of explaining how social capital will change along the lifecycle and why cooperative decision makers should try to maintain it during the development of cooperatives.

\subsection{Structural dimension}

The structural dimension of social capital reflects the overall pattern of social connections between the members of an organization, and the most important facets in this dimension include the network ties, network configuration and appropriability (Nahapiet and Ghoshal 1998).

Network ties describe the social connections between people in an organization. They are regarded as a fundamental aspect of social capital because 'an actor's network of social ties creates opportunities for social capital transactions' (Adler and Kwon 
2002; Inkpen and Tsang 2005). A cooperative is by design an organization with plenty of social ties among its members. It is formed by a group of farmers voluntarily to achieve their collective goals and interests. The members of a cooperative are not anonymous financiers but real persons who run their own agricultural enterprises (Nilsson et al. 2012). The collective ownership of the member group towards the downstream processor and the local nature of the cooperative entail that the members are likely to know each other and have social relationships (Cropp and Ingalsbe 1989; Nilsson et al. 2012). Therefore, there exists a social network among the members of a cooperative.

The configuration of a social network determines the pattern of linkages among network members, such as the network hierarchy and relationships density, etc. (Nahapiet and Ghoshal 1998). The social network in a cooperative is a combination of horizontal and vertical social ties. The horizontal ties represent the social relationships and interactions between members in the cooperative society. The vertical ties are the social connections between the members and the cooperative processor and management. In cooperatives, the Board of Directors is elected from the membership, and, historically, the CEO of a traditional cooperative is also a member. ${ }^{2}$ There is thus personal acquaintance between the members and cooperative leaders. Furthermore, as the members transact frequently with the cooperative processor, they meet with management in a personal way regularly (Hendrikse and Feng 2013). Close social relationships between them are expected to develop.

According to Bolino et al. (2002), 'network appropriability relates to the ease with which different types of relationships can be transferred within a network'. It measures the extent to which a relationship developed in one context can be (re)used in other contexts (Nahapiet and Ghoshal 1998; Pearson et al. 2008). Every cooperative represents simultaneously a social group and a joint enterprise (Valentinov 2004). As the joint enterprise is owned and operated by the same group of members, the pre-existing social relationships established between members in the community are thus transferred into the joint enterprise and its business. The members' economic activities in the cooperative are highly embedded in their social network.

The structural social capital of a cooperative can be measured by the strength of social ties, by the density of social network, and by the frequency of social interactions among the members. Gargiulo and Benassi (2000) summarize the previous research on social networks and conclude that "networks can help actors to coordinate critical task interdependencies and to overcome the dilemmas of cooperation and collective action'. Therefore, because a social network creates a platform for information sharing and exchange (Gulati 1995; Walker et al. 1997; Sparrowe et al. 2001), a high level of structural social capital is advantageous for both members and cooperatives. For individual members, strong ties with similar producers may lead to spill-over effects that result in an increase in efficiency and productivity (Levin and Reiss 1998). For the cooperative firm, the close social connections between members and managers may create a superior vertical information flow that significantly supports the collective activities (Hendrikse and Feng 2013).

\footnotetext{
${ }^{2}$ Nowadays, many cooperatives, especially in China, still use one of the members as a CEO, rather than hire an outsider. Conversely, in Western countries, especially in the US, most cooperatives employ outside CEOs. In Spain and Brazil, the situation is more mixed (Liang and Hendrikse 2013).
} 


\subsection{Cognitive dimension}

The cognitive dimension is the 'shared representations, interpretations and systems of meaning among parties, which reflects the members' collective understanding of the organization's culture, shared vision and purpose, common language and codes, etc.' (Nahapiet and Ghoshal 1998).

The cooperative culture, vision, and purpose are carried by the ideology and values of traditional cooperatives. They provide a good starting point for the members to develop mutual understanding. When farmers take collective actions to found a cooperative, they are supposed to agree on what their cooperative should do, and how to do it. They also acknowledge the proper way of acting in such a community. The cooperative principles such as the Rochdale principles contain a clearly discernible element of ideology describing these issues (Nilsson et al. 2012). In general, the cognitive foundation of cooperative values, norms and beliefs in traditional cooperatives is to emphasize service to members over profit, to subordinate individual goals to the good of the whole, and to value equality, etc. (Hogeland 2004). For example, in Sweden, the old farmers 'view the cooperative memberships as a way of showing solidarity with peers, economic aspects being of secondary importance' (Hakelius 1999:31).

A cooperative will also develop common language or a set of codes among the members. The geographical and production proximity entails that the members will have similar production and marketing problems and thus less disagreement (Hendrikse and Feng 2013). In addition, the frequent social interactions within the membership network and the repeated transactions between the members and the processor will also support the development of the system of shared meanings in the cooperative (Tsai and Ghoshal 1998; Wu 2008).

The cognitive social capital of a cooperative can be measured by the extent to which the members share congruent vision and goals. A high level of cognitive social capital benefits cooperatives in several ways. First, it supports the collective actions of members. People with shared vision are more willing to enter into cooperation (Tsai and Ghoshal 1998). In addition, Leana and Pil (2006) argue that the shared goals in a community can mitigate the free-riding problems and reduce the use of formal control mechanisms. Second, the cognitive social capital promotes successful coordination by facilitating effective communication and common perceptions among members. Inkpen and Tsang (2005) claim that, 'when a shared vision is present in the network, members have similar perceptions as to how they should interact with one another'. A shared vision provides members with the ability to communicate more effectively and avoid possible misunderstanding in communications (Tsai and Ghoshal 1998). In cooperatives, better communication increases the level of mutual understanding among members and helps them anticipate the actions of other members (Hendrikse and Feng 2013). This will lead to the cooperative's successful coordination of business activities and adaptation to changing situations.

\subsection{Relational dimension}

According to Nahapiet and Ghoshal (1998), the relational dimension of social capital is composed of 'trust, shared norms, perceived obligations, and a sense of mutual identification'. 
Trust is the key facet of the relational dimension of social capital (Nahapiet and Ghoshal 1998). Bolino et al. (2002) summarize the prior research (e.g. Putnam 1993; Tsai and Ghoshal 1998) and conclude that 'trust facilitates social and resource exchange, increases communication, and enhances cooperation between individuals'. When individuals trust each other, they are more likely to cooperate and participate in the collective actions (Gulati 1995). The value of trust has been widely studied in the cooperative literature. Researchers claim that cooperatives have greater organizational trust than IOFs do, which exist both among the members and between the members and processor (Shaffer 1987; Balbach 1998; Shapira 1999; Sykuta and Cook 2001; James Jr. and Sykuta 2005). The trust in the cooperative makes the members willingly identify themselves to the cooperative (Borgen 2001), be loyal to the cooperative (James Jr. and Sykuta 2006), and actively participate in the cooperative governance (James Jr. and Sykuta 2005; Österberg and Nilsson 2009; Barraud-Didier et al. 2012). The members' trust towards their cooperative also makes them willing to accept the control of the cooperative (Søgaard 1994) and leads to more efficient contracts between the members and processor (Balbach 1998). Ollila et al. (2011) claim that 'mutual trust between the membership and their cooperative has through history enabled both members and cooperatives to survive financially difficult times'.

A norm represents 'a degree of consensus in the social system' about the proper way to behave (Nahapiet and Ghoshal 1998). According to Coleman (1990), a norm exists 'when the socially defined right to control an action is held not by the actor but by others'. As a society with a dense social network and common ideology, a cooperative is supposed to develop social norms emphasizing cooperation, reciprocity, and loyalty. In cooperatives, members are willing to accept a high degree of social control via these norms (Nilsson et al. 2012). Social control can curb free-riding problems by making opportunistic behaviors more costly due to the threat of social sanctions and reputational effects (Granovetter 1985; Gulati et al. 2000). Therefore, the need for formal control can be reduced (Adler and Kwon 2002).

According to Nahapiet and Ghoshal (1998), 'obligations represent a commitment or duty to undertake some activity in the future'. Members' obligations towards the collective actions are crucial for cooperatives because their survival and success rely on the patronage and member commitment (Fulton and Adamowicz 1993). When members have a strong sense of obligation towards one another and towards their cooperative, they will commit themselves by actively patronizing the cooperative processor, providing risk capital, and participating in cooperative governance (Österberg and Nilsson 2009).

Finally, identification is defined as 'the process whereby individuals see themselves as one with another person or a group of people' (Nahapiet and Ghoshal 1998). It is members' sense of belonging to the cooperative. Group identity is beneficial for information exchange and cooperation (Nahapiet and Ghoshal 1998). It can also become a social motivation (Akerlof and Kranton 2005). In cooperatives, members' sense of identity can be induced by their common goals and a long history of social interactions. Gray and Kraenzle (1998) underline the strong identification of members with their cooperative. Members' identification with the cooperative is also a significant trust-making mechanism (Borgen 2001) and a source of members' commitment (Jussila et al. 2012).

The relational social capital can be measured by the amount of trust members place on each other and on management, by the strength of social norms in the community, 
and by the level of loyalty of members towards their cooperative. In general, the relational social capital serves as the key resource for creating cooperatives' comparative advantage over IOFs. Successful cooperatives are characterized by possessing a large stock of these relational social capital components, which facilitate the collaborative behaviors and collective actions of members. On the other hand, there is evidence showing that the future for cooperative business barely exists if there is no sufficient relational social capital, such as trust, commitment and loyalty, to support collective actions of farmers (e.g. Nilsson and Hendrikse 2011).

\subsection{Relation between different dimensions}

As Nahapiet and Ghoshal (1998) point out, although we can discuss the dimensions of cooperative social capital separately for analytical reasons, they are closely interrelated. We suggest that the three dimensions are complementary in nature, with each dimension reinforcing the other dimensions.

First, the structural dimension serves as an important resource for the creation of the other two dimensions (Tsai and Ghoshal 1998). Previous studies have suggested that social ties and interactions promote trust between individuals (Gulati 1995; Granovetter 1985; Arregle et al. 2007). Norms are more firmly held and easier to enforce in a denser social network (Granovetter 2005). In addition, the organization members' social ties and interactions support the formation of shared vision (Tsai and Ghoshal 1998) and altruisms (Dur and Sol 2010). It is easy for members to share common values and understanding of roles if they are closely connected (Podolny and Baron 1997). The closure of a social network also facilitates the development of high levels of relational and cognitive social capital (Nahapiet and Ghoshal 1998).

Second, Tsai and Ghoshal (1998) propose that 'the common values and a shared vision, the major manifestations of the cognitive dimension of social capital, encourage the development of trusting relationships'. Pearson et al. (2008) also argue that the cognitive dimension serves as an antecedent to the relational dimension. They suggest that 'a shared vision will lead to collective trust and norms for fulfilment of the common purpose' (p.958). In addition, the cognitive social capital also supports the development of the structural dimension because people who share the same mental model, language and values are more likely to interact with one another and exchange information regularly (Mohammed and Dumville 2001; Leana and Pil 2006).

Third, the relational dimension of social capital reinforces the creation of the other dimensions. As Nahapiet and Ghoshal (1998) argue, 'trust creates anticipation of value through social interactions with others and thus motivates actors to deepen relations and pursue interactions'. In addition, 'trusting relations allow for the transmission of more information as well as richer and potentially more valuable information' (Leana and Pil 2006).

\section{Social capital along the lifecycle of cooperatives}

The organization life cycle literature features various changes accompanying organization development and transition from one stage to the next (Jawahar and McLaughlin 2001; Lester et al. 2003). Social capital is closely bound with the development and 
strategy of the organization (Nahapiet and Ghoshal 1998). In this section, the evolution of social capital in a cooperative is contoured along the cooperative lifecycle. We aim to highlight the dynamics of social capital in cooperatives. Moreover, we explain the formation, growth, decline, and change of cooperative organizations from the lens of social capital and the coherence between social capital and governance structure, which are considered as informal institution and formal institution, respectively.

Cook (1995:1155) suggests a five-stage lifecycle model for cooperatives: '(1) economic justification and establishment, (2) survival of infant stage, (3) growth and consolidation, whereby problems of so-called vaguely defined property rights appear, (4) struggle against the vaguely defined property rights problems, (5) exiting, restructuring (including choosing a hybrid model and involving outside co-owners), or shifting (choosing an individualised cooperative model, including tradable delivery rights)'. We propose that cooperatives in different stages of the lifecycle are featured with different levels of social capital. Cooperatives are supposed to possess a high level of social capital in the early stages of the lifecycle, which forms a coherent system with the traditional cooperative governance structure. However, the level of social capital in cooperatives exhibits a declining trend along the development of the organization (Nilsson et al. 2012). We examine the ways in which certain organizational changes in cooperatives affect each social capital dimension. In the last stages of the lifecycle, a low social capital level in the cooperative is no longer aligned with the economic attributes featured by the collective governance structure. The imbalance of social capital and governance structure explains the cooperative's common property problems and loss of competiveness. We present some cases showing how cooperatives respond to the imbalance of social and economic attributes.

\subsection{Economic justification and establishment}

While economic justifications, such as correction of market failures and better prices, provide farmers various economic motives to form a cooperative, a high level of social capital among the potential members initializes their collective actions. Regarding the structural dimension, because most cooperatives start on a small scale, members are usually well acquainted with each other and there are strong social ties among them (Nilsson et al. 2012). The initial membership of cooperatives is mostly comprised of farmers from the local community who are formerly connected and know each other very well (Liang and Hendrikse 2013).

In a relatively small and close social network, the presence of frequent interactions, common interests, and similar backgrounds promotes the development of a shared vision in the community. Communication is effective in the social network and clear objectives of the cooperative can be developed. The social ties and common vision thus provide a condition for developing an initial coalition of potential members and the formation of a stable membership. In a case study of an organic vegetable cooperative in UK, a collective understanding of the organization's culture and purpose is emphasized as one of the most important conditions for the establishment of the cooperative (Liang et al. 2018).

The cooperative's formation also needs a high level of relational social capital. The pre-existing social ties provide information on potential members' trustworthiness and reliability. When the members pool their resources to form their cooperative, they 
create mutual dependence on each other. They must be confident that none will shirk their commitments as business partners. Therefore, trust among the farmers is crucial before they decide to invest time and money in the cooperative. The empirical study of cooperative membership in Macedonia demonstrates that a low level of trust between the farmers prevents them from taking any initiative in cooperative formation, although they have a need for cooperatives to correct market failures (Nilsson and Hendrikse 2011). In fact, even after cooperatives, such as those in Russia, have been established in a top-down way by governmental administration, these cooperatives have meagre survival chances when the trust within the membership is low (Nilsson and Hendrikse 2011).

Therefore, a high level of social capital can be regarded as the necessary condition for the formation of cooperatives. During the establishment stage, the level of social capital in a cooperative is high and it exists as a result of interpersonal relationships developed from the informal social interactions among the members. The trust among members and between members and management is high. Members are very loyal to their cooperatives and maintain a high level of commitment.

\subsection{Survival of infant stage}

In the second stage of the lifecycle, the main objectives of cooperatives are confronting market failure and generating more favorable prices than IOFs for their members. The key to survive this stage is that benefits outweighs costs (Cook 1995). It is therefore important that social capital supports the cooperative business through promoting cooperation and improving coordination and operating efficiency. The structural dimension of social capital is manifested as the social ties and interactions in the cooperative community. It supports the dispersion of production technology and knowledge among the members (Peterson and Anderson 1996).

By facilitating common language and meanings, the cognitive social capital supports the collective actions of the members by improving communication efficiency. In addition, when there are mutual understandings and common goals among the members, a consensus in decision-making is easy to achieve. The costs associated with collective decision-making in the cooperative are thus low.

Relational social capital strongly benefits cooperatives by serving as social mechanisms supporting both coordination and control. According to Borgen (2001), coordination and control in cooperatives cannot be fully accomplished by means of prices or authority. Successful cooperatives are characterized by their capacity to overcome this gap with the strength of relational social capital, featured by a high level of trust and strong social norms. As the trust between members makes them believe that nobody will shirk his duties, the cooperative is able to reduce the time and costs spent on expensive controlling measures such as formal contracts, information gathering, monitoring, and surveillance. Social norms in the cooperative mitigate the opportunistic behaviors and generate certain routines in transactions and collective actions. The costs of formal control and coordination are further saved. As such, the informal mechanisms steered by the relational social capital play a crucial role in the early stage of cooperative development.

Chloupkova et al.'s (2003) case study of the Danish cooperative dairy movement highlights the value of a high social capital level. From 1882, an increasing number of 
Danish peasants committed themselves to deliver all their milk to their own cooperatives. The cooperatives were formed by circles of energetic entrepreneurs in the local rural communities and 'valuable social capital was created bottom-up' (p.243). The cooperative dairies became very successful and the quality of the butter was increased. It became possible to standardize output and thus demand higher prices. The social control mechanism guaranteed that none of the members would cheat on quality and the milk was delivered in good condition. In general, as a high level of social capital reduces the tendencies to free ride and default for individual advantage (Paldam and Svendsen 2000), it guaranteed the milk quality under complete pooling while no strict formal control was provided at such an early stage of the Danish dairy cooperatives. Recent evidence from Kenya and China also shows that the observed differences in the performance of producer cooperatives can be explained by the differences in the organizations' social capital levels (Wambugu et al. 2009; Liang et al. 2015).

\subsection{Growth and consolidation}

In stage three of the lifecycle, successful cooperatives become large and complex by expanding horizontally and vertically. Conflicts, i.e. free rider, horizon, portfolio, control, and influence cost problems, arise due to the vaguely defined property rights over residual claims and decision control. However, while facilitating the growth and competitiveness of cooperatives, the social capital level in cooperatives may decline gradually and become quite low in large and complex cooperatives (Nilsson et al. 2012). First, the structural social capital decreases. The expansion of the cooperative will create a large and heterogeneous membership (Nilsson et al. 2012). It becomes infeasible for members to maintain social connections with most people in a large society. As a consequence, the social ties between members become weaker, the cohesiveness of member community disappears, the distance between members and management increases, and communication problems emerge (Nilsson et al. 2009; Österberg and Nilsson 2009). The technological developments such as electronic transactions, which have increasingly replaced face-to-face transactions, may also hamper the development and maintenance of intimate connections between members and the cooperative (Byrne and McCarthy 2005). When the cooperative becomes large, it needs to hire professional executives who are not from the membership (Feng 2011). Information asymmetry between the members and the professional management may increase (Nilsson and Hendrikse 2011). In addition, as the cooperative develops, members have decreasing involvement in the cooperatives' decision making and management becomes increasingly autonomous (Bager 1996; Harte 1997; Bhuyan 2007; Bijman et al. 2013). The case study of the cheese cooperative De Producent in Gouda, the Netherlands, provides a good example (Peng et al. 2016). In the past two decades, most of the active members of the cooperative developed from farming households into modern farming enterprises, which are managed by professional teams and have large scales of production. Some of them reach an annual revenue of more than one million Euros. The members spread in the radius of $100 \mathrm{~km}$ around Gouda. They focus mainly on the production activities and rarely interact with each other. The communication is mainly between the members and the cooperative processor. In such a modern cooperative, there is no much space for members to develop social ties between each other.

Second, the large and heterogeneous membership has detrimental effects on the cognitive social capital. According to Hogeland (2006), the culture of traditionally 
organized cooperatives vanishes gradually as the cooperative expands. The social interactions in cooperatives, which serve as the mechanism to develop and maintain shared beliefs and values, become less frequent when the cooperative membership is large. The pronounced heterogeneity in membership, such as size, geographical location, knowledge, interests, even nationality, makes it difficult for members to develop common values and organizational language. Moreover, cooperative ideology plays a less prominent role in cooperatives nowadays. According to Fulton (1995), changes in society's values are likely to make cooperation more difficult. Profitability becomes the priority of the members. Farmers today, especially the young generation of farmers, are more pragmatic about their cooperatives and members' decisions are based mainly on economic terms (Hakelius 1999; Karantininis and Zago 2001).

Finally, following the decline of the structural and cognitive social capital, the relational social capital decreases. Horizontally, with less interaction in the membership, the traditional conditions for personal trust building are no longer in place (Granovetter 1985). At the same time, 'the larger the group, the lower is its ability to crystallize and enforce norms, including those against free-riding behaviors' (Granovetter 2005). Bijman and Verhees (2011) also find that members' commitment decreases in the geographical size of cooperatives. Vertically, Hogeland (2006) argues that the stricter hierarchical control mechanisms demanded by the vertical coordination may lead to a negative attitude and commitment of the members towards their cooperatives. The lack of communication between the members and cooperative leaders will lead to low trust of members in management. The shrinking members' control in large cooperatives makes the members care less about the governance of their cooperative and increase the agency costs. As the cooperative becomes large, it acts more like IOFs, and becomes more corporate-oriented (Hind 1997, 1999; Nilsson and Ollila 2009). The identification of members with the cooperative weakens (Borgen 2001). 'Members consider their relationship with the cooperative purely in business terms' (Ollila et al. 2013), and the behavioral constraints that social mechanisms can place on members are much weaker.

The decrease of social capital in a cooperative in its expansion stage can be attributed to the change in factors that shape the evolution of social capital, namely, time, interaction, interdependence and closure (Nahapiet and Ghoshal 1998). In general, the expansion of a cooperative over time may change all or most of these factors by modifying the social structure of a cooperative community, decreasing the possibility of interactions among members, lowering the interdependency between members, and weakening the identity of membership. Consequently, the trust, common vision, loyalty and other elements of social capital disappear in the minds of the members. The extent of social capital decline may vary among countries/regions, depending on the high-level culture. The decline of social capital in cooperatives in some Asian countries, especially in China where the social harmony culture dominates, may be gentler (Bernardi and Miani 2014).

\subsection{Struggle against the vaguely defined property rights problems}

In stage four of the lifecycle, cooperatives are confronted with more serious conflicts of property rights issues. Cooperatives therefore begin to struggle for decisions regarding exit, continue, and transition, based on the trade-offs between vaguely defined property 
rights and unique benefits such as the elimination of the double mark-up and the competitive yardstick (Cook 1995; Liang and Hendrikse 2016). The common property rights in cooperatives are based on a high degree of collectivism. When there is insufficient social capital to support the collectivism in the governance structure, the common property rights structure is no longer appropriate. The vaguely defined property rights problems surface and become acute (Nilsson et al. 2012). Essentially, these problems are rooted in the imbalance of the social and economic attributes of cooperatives. In other words, the governance structure featured by collective income and decision rights allocation is no longer coherent with the decreasing social capital level.

Therefore, the vaguely defined property rights problems are typically interrelated with the low level of social capital in cooperatives. Borgen (2004) states that the adverse consequences of the common property rights are expected to appear in the form of weak membership commitment. The combination of traditional equitable policies and a low level of social capital may cause free-riding problems and the adverse selection of efficient members (Hendrikse 2011; Pennerstorfer and Weiss 2013). In addition, the decrease of the social capital level forms a vicious cycle with the vaguely defined property rights problems. For example, if members don't have trust in their cooperative's long-run perspective, they will have a strong desire for low retained earnings and a short redemption period, reflected as the horizon problem. On the other hand, the members who become dissatisfied with the common property rights will continuously lose their loyalty towards their cooperative. As such, a low level of social capital aggravates the vaguely defined property rights problems, and in turn, these problems further erode cooperative social capital. As the low social capital level jeopardizes the foundation of the collective governance structure of the cooperative, the cooperative loses its competiveness gradually and faces the risk of being abandoned by its members. At the end of stage four, some cooperatives recognize the imbalance of the social and economic attributes of cooperatives and consider options for change, which leads to stage five of the lifecycle.

\subsection{Exit, restructuring, or shifting}

In attempting to solve the vaguely defined property rights problems, cooperatives choose among three aforementioned strategies (Cook 1995). Some choose the exit strategies of liquidation, some convert to an IOF structure, and others stay with the cooperative form but decide to restructure or shift the governance structure.

One governance structure restructuring strategy cooperatives can adopt is to change their collective income rights structure into more individualistic forms, e.g. replacing complete pooling with partial or no pooling, introducing individualized and tradable ownership rights, differentiated member treatment, etc. (Chaddad and Cook 2004; Hendrikse 2011). These solutions can be seen as a strategic move of cooperatives to align their economic attributes with the new status of the social attributes. The Greenery is an example of cooperative development and restructuring during stage three to stage five of the cooperative lifecycle. Specifically, The Greenery chose to convert its income rights structure from a collective to an individualistic form (Hendrikse 2011).

The Greenery is a leading fruit and vegetable company in Europe. As the outcome of a merger of nine Dutch regional fruit and vegetable auction cooperatives, the new 
cooperative has been struggling in implementing its new strategy and in finding the most appropriate organization (Bijman 2002; Hendrikse 2011). Besides the large size (approximately 9000 members), The Greenery's membership heterogeneity increased due to the fact that 'consumers' demand for more variety and higher quality has induced some growers to innovate' (Hendrikse 2011). In the first few years after the merger, some large growers left the cooperative because of 'cross-subsidization of small growers' (Bijman and Hendrikse 2003). Meanwhile, some innovative producers also left because the equality principle of pooling limits the payoff they could receive for their innovation efforts (Hendrikse 2011). Explained from the social capital perspective, The Greenery, as a large and complex cooperative, has difficulty in maintaining social capital in the organization. As Bijman (2002) points out, the organizational changes after the merger resulted in dissatisfaction among growers and part of the dissatisfaction was caused by 'a lack of communication between The Greenery and members'. Members' loyalty and commitment is no longer in place to serve as their social motivation to stay with and deliver to the cooperative. Driven mainly by economic benefits, the members who are not compensated for their higher product quality or larger volume would simply leave the cooperative to trade with IOFs or form a new cooperative. This process was finally countered by the introduction of member benefit programs in The Greenery, which 'increased the number and extent of quality attributes covered by specific clauses in the incentive contracts' (Hendrikse 2011). It entails that members realize the payoff for higher product quality by receiving a quality-specific price. With the member benefit programs, the cooperatives adopted strong and individualistic quality incentives. The Greenery case illustrates the necessity of adjusting the income rights structure according to the cooperative's social attributes. In a large and complex cooperative with heterogeneous membership, when social capital seems to have played a limited role in members' decision making, adopting individualistic income rights allocation is necessary.

Instead of changing the income rights structure, cooperatives can also choose to maintain or recover social capital during the development of the organization. Although it may become increasingly difficult as the membership base expands and becomes more heterogeneous (Valentinov 2004), it can still be very successful. However, as social capital takes a long time to build, it thus requires management's continuous efforts and great endeavor (Putnam 1993).

Table 1 summaries the changes of each dimension of social capital along cooperative life cycle. A cooperative is characterized by a high level of social capital featured by the strong social ties, common vision, and high trust within the membership. During the early stages of life cycle. Different dimensions of social capital are mutuallyreinforcing and complementary to each other. The governance structure of the cooperative is featured by the collective income and decision rights allocation. A unique feature of cooperatives' income rights structure is that members hold the residual claims collectively and receive benefits proportional to their patronage (Dunn 1988). Pooling is a prominent element in the income rights structure of traditional cooperatives. It entails that 'revenues and costs are to a certain extent allocated independent of quantity and/or quality' (Hendrikse and Feng 2013). The members thus receive collective instead of individualistic incentives for their patronage. Regarding decision rights, members usually have equal voting power and make decisions collectively based on the one-member-one-vote principle (Hansmann 1996). With the collective 


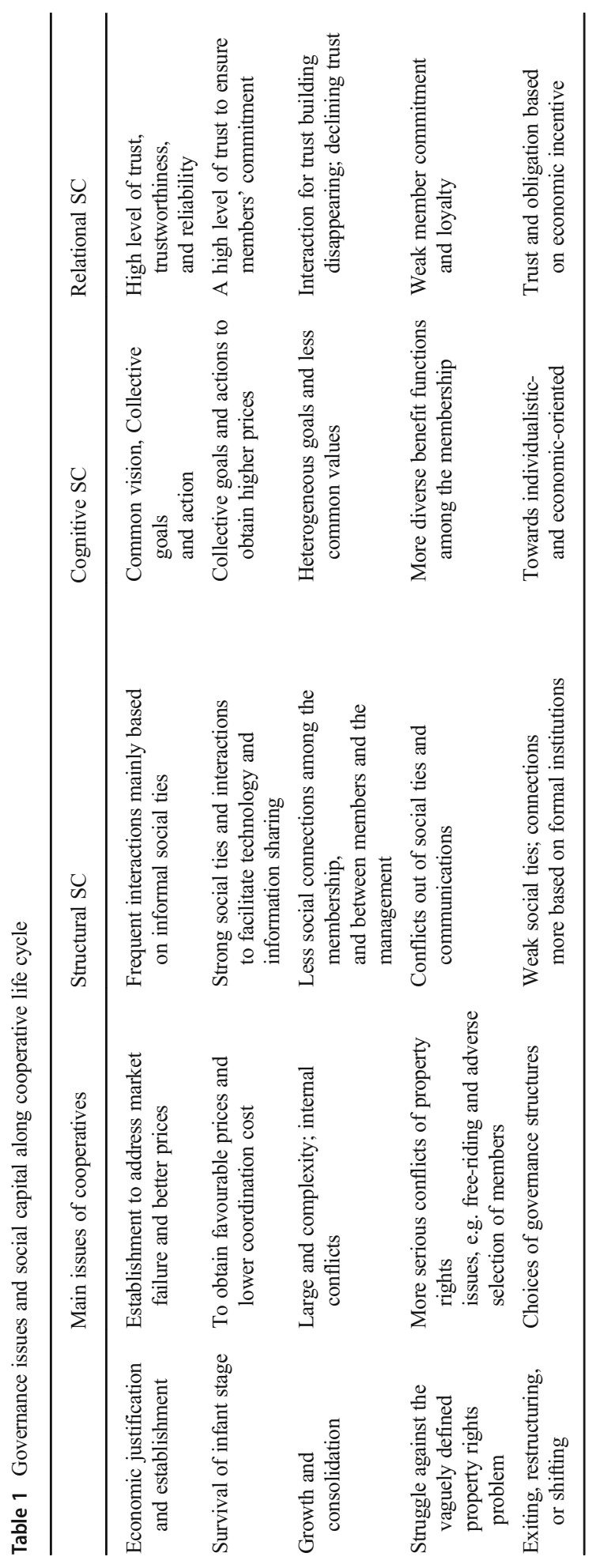


governance structure, traditional cooperatives are supposed to face organizational inefficiencies due to the opportunistic behaviors and high collective decision-making costs. However, the presence of a high level of social capital complements the collective governance structure by controlling and coordinating the members' activities via social mechanisms.

Let's take the other polar of governance structure, an IOF, as an example of the choice of the last stage. An IOF has a different set of social and governance attribute values featured by a relatively low social capital level in combination with an individualistic governance structure. It is owned by investors and it primary goal is to give its investors the highest investment return. The farmers are only the suppliers of the IOF and the relationship between the farmers and the IOF is seen as solely seller-buyer. The farmers, as individual suppliers, are not supposed to socialize with each other as frequently as the cooperative members will do. Therefore, there is a low social capital level among the farmers, and between the farmers and the IOF. When the farmers deliver their produce to the IOF, they receive an individual instead of a pooled price. The economic incentives are individualized. The investors of the IOF are the holders of decision rights, although these rights are usually delegated to the CEO, who 'often has substantial control over setting, ratifying and implementing company policy' (Hendrikse and Feng 2013). In the IOF, economic incentives instead of social mechanisms play the dominant role of controlling and coordinating economic activities. The individualistic governance structure is thus coherent with the low social capital level.

We argue that the cooperative and the IOF are both efficient because their social and governance attributes are coherent. Changing the value of a particular without changing the values of other attributes may lead to a serious loss in the organizational efficiency (Milgrom and Roberts 1990; Brynjolfsson and Milgrom 2013). Liang et al. (2018) report that social capital in cooperatives featured by a high level of collective governance structure plays a more important role than that in cooperatives with a lower level of collective income rights. For the cooperative, if one or some values of its social attributes change, the cooperative may become inefficient if the collective income or decision rights allocation in the governance structure remain the same. To avoid organizational inefficiency and failure, a new combination of attribute values must be forged.

\subsection{Management implications}

In this section, we focus on the implications of the study of social capital for the management practice in cooperatives and discuss how cooperatives can maintain and recover social capital.

Agricultural cooperatives have been faced with the challenges of new market conditions. To respond to the intensified competition and differentiated demands of the market, many cooperatives choose to expand horizontally or/and vertically. As a consequence, cooperatives become large in size and complex in organizational structure. Meanwhile, cooperatives start to adopt the competitive strategies and control mechanisms similar to those used usually by the IOFs (Bijman and Wollni 2009). Cooperatives nowadays are becoming more and more akin to IOFs, and gradually, 'members consider their relationship with the cooperative purely in business terms' (Ollila et al. 2013). However, all these strategies of a cooperative aiming for economic 
success are at the cost of its social capital, which happens to be the cooperative's comparative advantage over IOFs. Nilsson et al. (2012) warn that:

'If a cooperative is not aware of its comparative advantage in terms of social capital, and therefore does not protect it, it risks losing this form of capital in the process of developing into a large-scale enterprise. Consequently, profits from economies of scale and scope may be outweighed by loss of social capital mirrored in less trust among members and between members and leaders, alienation and passivity among members, low involvement, weak democratic governance, private good provision rather than collective good provision, widespread free riding, low satisfaction, and loss of solidarity.'

Cooperatives largely rely on members' collective actions. Our discussion of cooperative social capital along the lifecycle suggests that social capital can be regarded as a key success factor of cooperatives. Therefore, when cooperatives respond to changing market conditions and modify their structures from the traditional to innovative forms, they must develop means to maintain or even increase social capital (Ollila et al. 2013). The primary mechanisms by which social capital can be maintained and increased reside in each social capital dimension. First, as the structural dimension serves as the basic resource for the creation of social capital, the most obvious way for a cooperative to build social capital is to foster the social relationships among its members (Leana et al. 1999). Cooperatives should invest in maintaining the membership network by promoting social interactions between members. This can be done by creating social events and gatherings of members, developing an appropriate communication policy, organizing workshops and training seminars, and so on. In addition, cooperatives should put efforts into keeping the membership stable. According to Inkpen and Tsang (2005), 'a highly unstable network may limit the opportunities for the creation of social capital, because when an actor leaves the network, ties disappear'.

Second, the cognitive dimension can be developed through the effective communication of cooperatives' shared goals and values. Cooperatives should provide education about the nature and benefits of cooperation to members to reinforce the cooperative ideology (Byrne and McCarthy 2005). For instance, before launching the new payment scheme, Friesland Campina, one of the largest dairy cooperatives in the world, spent one year in conveying the message to members about the market potential of lactose and explaining to them why the cooperative should increase the investment of the value-added products in that area. These member education programs help members understand the businesses with which they are unfamiliar and win their common understanding. Cooperatives can also establish a shared vision by selecting and rewarding members who value working collectively (Leana et al. 1999). As frequent interactions evoke the development of shared language and understanding among group members, the suggested investment in the structural dimension will also benefit the growth of cognitive social capital.

Finally, drawing on the discussion in Section 2, the relational dimension is highly dependent on the development of the first two dimensions. Consistent with this idea, the cooperative's investment in the structural and cognitive dimension will ultimately lead to the development of its relational social capital. For example, frequent communication between the members and management will enhance the trust and loyalty of 
members towards the cooperative (Barraud-Didier et al. 2012). Trechter et al. (2002) also show that cooperative communication strategies have the potential to increase members' commitment. In addition, cooperatives should develop measures to encourage members to participate in cooperative governance. Previous study suggests that members' access to information and their feeling of control over the cooperative strengthen their trust and commitment (e.g. Fulton 1999; Birchall and Simmons 2004; Byrne and McCarthy 2005; Österberg and Nilsson 2009). Finally, the case of CRS described in the previous section provides an illustrative example of recovery of social capital through strengthening cooperative identity.

Furthermore, cooperatives should pay attention to the complex relationship between social capital and governance structure. In the last stages of the lifecycle, many cooperatives confront the vaguely defined property rights problems by introducing individualistic income rights structure and transferable and appreciable equity shares. This change of cooperative governance structure provides members with more economic motivation for patronage commitment and equity contribution. However, the consequence of this motivation on cooperative social capital is still unclear. One possibility is that the new governance structure with strong and individualistic economic incentives will lead to economic success of the cooperative and social capital is, in turn, reinforced by the economic success. This phenomenon can be found in the CRS case described above. Cechin et al. (2013) also find that stricter hierarchical control mechanisms actually have a positive effect on members' commitment. In this situation, the individualistic governance structure and a high social capital level form a new coherent system of attributes. Another possibility is that strong and individualistic economic incentives in combination with formal control mechanisms will crowd out the intrinsic motivation of members and suppress trust (Malhotra and Murnighan 2002; Bowles and Polania-Reyes 2012). It decreases the cooperative's social capital level. Ultimately, the cooperative is featured by an individualistic governance structure and a low social capital level in the system of attributes, which is similar to IOFs. Therefore, a better understanding of both possibilities is crucial for cooperative leaders when they consider the change in governance structure.

\section{Conclusion and further research}

In this paper, we seek to understand how social capital exists within cooperatives and how social capital affects the cooperative business. We adopt Nahapiet and Ghoshal's (1998) conceptualization of social capital, and provide an integrated analysis of the structural, cognitive and relational dimensions of social capital in cooperatives. Specifically, we complement the previous research on cooperative social capital by delineating the links between the three dimensions of social capital and the governance structure of cooperatives.

The second focus of this paper is to study the social capital in cooperatives from the perspective of the cooperative lifecycle. During the early stages of the lifecycle, the social capital level in cooperatives is high. It serves as the basis for the formation, survival, and success of cooperatives. The high level of social capital in cooperatives deters free-riding behavior and promotes stable cooperation among members. However, social capital in cooperatives will decline as the cooperatives become large in size 
and complex in structure. Cooperatives' market-oriented strategies and approaches of horizontal and vertical expansion may bring economic success, but in the meantime, the loss of social capital may outweigh the economic gain. When the low level of social capital upsets the balance between social and economic attributes, the cooperative may lose its efficiency. Cooperatives in this stage of the lifecycle shall adopt strategies that can rebalance the social and economic attributes, either by restoring cooperative social capital or by changing the income rights structure.

In order to maintain organizational social capital, it is important for the organization and its members to understand the benefits and value of social capital. Therefore, cooperative leaders shall be aware of the differences between cooperatives and IOFs and pay special attention to the social attributes of their organizations. Moreover, management shall elicit efforts of members in maintaining social capital in their cooperatives. We offer some suggestions on maintaining and restoring social capital in large and modern cooperatives. These measures cover the different dimensions of social capital. In addition, as the relationship between social capital and governance structure is still equivocal, cooperatives should take the potential costs of social capital into consideration when any decision of cooperative restructuring is made.

Given the significant importance of cooperative social capital, further research on this topic is warranted. We would like to suggest some avenues for further theoretical and empirical work. First of all, researchers can further explore the dimensions of social capital to identify the means by which these dimensions affect each other and affect other important organizational outcomes. One shortcoming of the previous research of social capital in cooperatives is the weak empirical support on many specific predictions of the value of social capital. Thus, further empirical research is highly desirable. The outcome of this type of research will provide practical implications for cooperative decision makers who want to maintain and recover cooperative social capital effectively and, in turn, sustain cooperatives' comparative advantage.

Second, we analyze the internal social capital of cooperatives on the organizational level in this paper, although the external/bridging social capital held by specific individuals may affect the behavior of the individuals and the performance of organizations as well (Burt 1992). External social capital is often operationalized in research as the social connections held by top managers (Leana and Pil 2006). The research on Chinese cooperatives shows that, the CEO and core members play an important role in their cooperative due to their rich external contacts and social resources (Liang 2013; Liang et al. 2015). This type of social capital is beyond the scope of the present paper and deserves more investigation.

Finally, the studies of social capital in cooperatives only focus on the positive side of social capital so far. However, social capital may also have a 'dark side' (Nooteboom 2007). The cohesiveness of a cooperative society may be harmful for the cooperative development in some respects. For example, Leana et al. (1999) point out the maintenance costs associated with social capital. In addition, excessive social capital may also result in an overly closed network, limiting access to external resources, and impeding actors' ability to adapt to changing task environments (Uzzi 1997). The trade-off between the positive and negative impacts of the social capital needs to be evaluated further. 
Acknowledgements This study was funded by the Natural Science Foundation of Zhejiang Province (Grant No. LY19G030030) and the National Natural Science Foundation of China (Grant No. 71573227).

Funding This study was funded by the Natural Science Foundation of Zhejiang Province (Grant No. LY19G030030) and the National Natural Science Foundation of China (Grant No. 71573227).

\section{Compliance with ethical standards}

Conflict of interest There is no conflict of interest.

\section{References}

Adler PS, Kwon S (2002) Social capital: prospects for a new concept. Acad Manag Rev 27:17-40

Akerlof GE, Kranton RE (2005) Identity and the economics of organizations. J Econ Perspect 19(1):9-32

Arregle J, Hitt MA, Sirmon DG, Very P (2007) The development of organisational social capital: attributes of family firms. J Manag Stud 44(1):73-95

Bager T (1996) Organisations in sectors. Explaining the dissemination of populations of formal organization in economic sectors - bridging rational choice and institutional approaches. South Jutland University Press, Esbjerg

Barraud-Didier V, Henninger M-C, Akremi AE (2012) The relationship between members' trust and participation in the governance of cooperatives: the role of organisational commitment. Int Food Agribusiness Mgnt Rev 15(1):1-24

Bernardi A, Miani M (2014) The long march of Chinese co-operatives: towards market economy, participation, and sustainable development. Asia Pacific Business Rev 20(3):330-355

Bhuyan S (2007) The people factor in cooperatives: an analysis of members' attitudes and behavior. Can J Agric Econ 55(3):275-298

Bijman, W.J.J. (2002). Essays on Agricultural Cooperatives: Governance Structure in Fruit and Vegetable Markets. Ph.D. Thesis, EPS-2002-015-ORG, ISBN: 90-5892-024-0, Rotterdam School of Management, Erasmus University, Rotterdam, The Netherlands

Bijman, W.J.J. and Verhees, V. (2011). Member or customer? Farmer commitment to supply cooperatives. Paper for the 5th international conference on economics and Management of Networks (EMNet), held in Limassol, Cyprus, on December 1-3, 2011

Bijman WJJ, Hendrikse GWJ (2003) Co-operatives in chains: institutional restructuring in the Dutch fruit and vegetable industry. J Chain Network Sci 3(2):95-107

Bijman WJJ, Wollni M (2009) Producer organizations and vertical coordination: an economic organization theory perspective. In: Rösner HJ, Schulz-Nieswandt F (eds) Beiträge der genossenschaftlichen Selbsthilfe zur wirtschaftlichen und sozialen Entwicklung. LIT-Verlag, Berlin, pp 231-252

Bijman WJJ, Hendrikse GWJ, van Oijen AA (2013) Accommodating two worlds in one organization: changing board models in agricultural cooperatives. Manag Decis Econ 34:204-217

Birchall J, Simmons J (2004) What motivates members to participate in co-operative and mutual businesses? A theoretical model and some findings. Annals Publ Cooperative Econ 75(3):465-495

Boland RJ, Tenkasi RV (1995) Perspective making and perspective taking in communities of knowing. Organ Sci 6:350-372

Bolino MC, Turnley WH, Bloodgood JM (2002) Citizenship behavior and the creation of social capital in organizations. Acad Manag Rev 27:505-522

Bonus H (1986) The cooperative association as a business enterprise: a study of the economics of transactions. J Inst Theor Econ 142(2):310-339

Borgen SO (2001) Identification as a trust-generating mechanism in cooperatives. Annals Publ Cooperative Econ 72(2):208-228

Borgen SO (2004) Rethinking incentive problems in cooperative organizations. J Socio-Econ 33:383-393

Bowles S, Polania-Reyes S (2012) Economic incentives and social preferences: substitutes or complements? J Econ Lit 50(2):368-425

Brynjolfsson E, Milgrom P (2013) Complementarity in organizations. In: Gibbons R, Roberts J (eds) The handbook of organizational economics. Princeton University Press, Princeton, pp 11-55

Burt RS (1992) Structural holes: the social structure of competition. Harvard University Press, Cambridge 
Byrne N, McCarthy O (2005) An analysis of the credit union's use of Craig's commitment building measures. J Co-Operative Stud 38(1):20-27

Cechin A, Bijman J, Pascucci S, Omta O (2013) Decomposing the member relationship in agricultural cooperatives: implications for commitment. Agribusiness 29:39-61

Chaddad FR, Cook ML (2004) Understanding new cooperative models: an ownership control rights typology. Rev Agric Econ 26:348-360

Chloupkova J, Svendsen GLH, Svendsen GT (2003) Building and destroying social capital: the case of cooperative movements in Denmark and Poland. Agric Hum Values 20:241-252

Coleman JS (1990) Foundations of social theory. Harvard University Press, Cambridge

Cook ML (1995) The future of US agricultural cooperatives: a neo-institutional approach. Am J Agric Econ 77(5):1153-1159

Cropp, R. and Ingalsbe, G. (1989). Structure and scope of agricultural cooperatives. In Cobia, D. (eds.), Cooperatives in agriculture. Prentice Hall

De Carolis DM, Saparito P (2006) Social capital, cognition, and entrepreneurial opportunities: A theoretical framework. Entrepreneurship Theory \& Practice 30(1):41-56

Dunn JR (1988) Basic cooperative principles and their relationship to selected practices. J Agricult Coop 3:83-93

Dur R, Sol J (2010) Social interaction, co-worker altruism, and incentives. Games Econ Behavior 69:293-301

Feng, L. (2011). Motivation, Coordination and Cognition in Cooperatives. Ph.D. Thesis, EPS-2010-220ORG, ISBN 978-90-5892-261-8, Rotterdam School of Management, Erasmus University, Rotterdam, The Netherlands

Feng L, Friis A, Nilsson J (2016) Social capital among members in grain marketing cooperatives of different sizes. Agribusiness 32(1):113-126

Fulton M (1995) The future of cooperatives in Canada: a property rights approach. Am J Agric Econ 77:1144 1152

Fulton M (1999) Cooperatives and member commitment. Finnish J Business Econ 4:418-437

Fulton JR, Adamowicz WL (1993) Factors that influence the commitment of members to their cooperative organization. J Agric Coop 8:39-53

Gargiulo M, Benassi M (2000) Trapped in your own net? Network cohesion, structural holes, and the adaptation of social capital. Organ Sci 11(2):183-196

Granovetter M (1985) Economic action and social structure: the problem of embeddedness. Am J Sociol 91(3):481-510

Granovetter M (2005) The impact of social structure on economic outcomes. J Econ Perspect 19(1):33-50

Gray, T.W. and Kraenzle, C.A. (1998). Member participation in agricultural cooperatives: a regression and scale analysis. USDA RBS research report 165, U.S. Department of Agriculture, Washington, D.C.

Gulati R (1995) Does familiarity breed trust? The implications of repeated ties for contractual choice in alliances. Acad Manag J 38:85-112

Gulati R, Norhria N, Zaheer A (2000) Strategic networks. Strateg Manag J 21:203-215

Hakelius K (1999) Farmer cooperatives in the 21st century: young and old farmers in Sweden. J Rural Cooperation 27(1):31-54

Hansen MH, Morrow JL Jr, Bastista JC (2002) The impact of trust on cooperative membership retention, performance, and satisfaction: an exploratory study. Int Food Agribusiness Manag Rev 5:41-59

Hansmann H (1996) The ownership of Enterprise. The Belknap Press of Harvard University Press, Cambridge

Harte LN (1997) Creeping privatisation of the Irish co-operatives: a transaction cost explanation. In: Nilsson J, van Dijk G (eds) Strategies and Structures in the Agro-food Industries. van Gorcum, The Netherlands, pp 31-53

Hendrikse GWJ (1998) Screening, competition and the choice of marketing cooperative as an organisational form. J Agric Econ 49(2):202-217

Hendrikse GWJ (2011) Pooling, access, and countervailing power in channel governance. Manag Sci 57(9): $1692-1702$

Hendrikse, G.W.J. and Feng, L. (2013). Interfirm cooperative. In Anna Grandori (eds.), Handbook of economic organization: integrating economic and organization theory: 501-521. Edward Elgar Publishing

Hendrikse GWJ, Veerman CP (2001a) Marketing cooperatives and financial structure: a transaction costs economics analysis. Agric Econ 26(3):205-216

Hendrikse GWJ, Veerman CP (2001b) Marketing co-operatives: an incomplete contracting perspective. J Agric Econ 52(1):53-64

Hind AM (1997) The changing values of the cooperative and its business focus. Am J Agric Econ 79:1077-1082

Hind AM (1999) Co-operative life cycle and goals. J Agric Econ 50:536-548

Hueth B, Marcoul P (2009) Incentive pay for CEOs in cooperative firms. Am J Agric Econ 91(5):1218-1223

Hogeland JA (2004) How culture drives economic behavior in cooperatives. J Rural Coop 32(1):19-36 
Hogeland JA (2006) The economic culture of U.S. agricultural cooperatives. Cultural Agric 28(2):67-79

Inkpen AC, Tsang EWK (2005) Social capital, networks, and knowledge transfer. Acad Manag Rev 30(1): 146-165

James HS Jr, Sykuta ME (2005) Property right and organizational characteristics of producer-owned firms and organizational trust. Annals Publ Coop Econ 76(4):545-580

James HS Jr, Sykuta ME (2006) Farmer trust in producer- and investor-owned firms: evidence from Missouri corn and soybean producers. Agribusiness: An Int J 22(1):135-153

Jawahar IM, McLaughlin GL (2001) Toward a descriptive stakeholder theory: an organizational life cycle approach. Acad Manag Rev 26(3):397-414

Jussila I, Byrne N, Tuominen H (2012) Affective commitment in co-operative organizations: what makes members want to stay? Int Bus Res 5(10):1-10

Karantininis K, Zago A (2001) Cooperatives and membership commitment: endogenous memberships in mixed duopsonies. Am J Agric Econ 83:1266-1272

Kraft PS, Brasch A (2018) Managerial social networks and innovation: a meta-analysis of bonding and bridging effects across institutional environments. J Prod Innov Manag 35(6):865-889

Levin RC, Reiss PC (1998) Cost-reducing and demand-creating R\&D with spillovers. RAND J Econ 19(4): $538-556$

Leana CR, van Buren HJ, III (1999) Organizational social capital and employment practices. Acad Manag Rev 24:538-555

Leana CR, Pil FK (2006) Social capital and organizational performance: evidence from urban public schools. Organ Sci 17:353-366

Lester DL, Parnell JA, Carraher S (2003) Organizational life cycle: A five-stage empirical scale. Int J Organizational Analysis 11(4):339-354

Liang, Q. (2013). Governance, CEO Identity, and Quality Provision of Farmer Cooperatives. Ph.D. Thesis, EPS-2013-281-ORG, ISBN 978-90-5892-325-7, Rotterdam School of Management, Erasmus University, Rotterdam, The Netherlands

Liang Q, Hendrikse GWJ (2013) Cooperative CEO identity and efficient governance: member or outside CEO? Agribusiness 29(1):23-38

Liang Q, Hendrikse G (2016) Pooling and the yardstick effect of cooperatives. Agric Syst 143:97-105

Liang Q, Huang Z, Lu H, Wang X (2015) Social capital, member participation, and cooperative performance: evidence from China's Zhejiang. Int Food Agribusiness Manag Rev 18(1):49-78

Liang Q, Lu H, Deng W (2018) Between social capital and formal governance in farmer cooperatives: evidence from China. Outlook Agric 47(3):196-203

Malhotra D, Murnighan JK (2002) The effects of contracts on interpersonal trust. Adm Sci Q 47:534-559

Milgrom P, Roberts J (1990) The economics of modern manufacturing: technology, strategy, and organization. Am Econ Rev 80(3):511-528

Mohammed S, Dumville BC (2001) Team mental models in a team knowledge framework: expanding theory and measurement across disciplinary boundaries. J Organ Behav 22:89-106

Mors ML (2010) Innovation in a global consulting firm: when the problem is too much diversity. Strateg Manag J 31(8):841-872

Nahapiet J, Ghoshal S (1998) Social capital, intellectual capital, and the organizational advantage. Acad Manag Rev 23(2):242-266

Nilsson J, Hendrikse GWJ (2011) Gemeinschaft and Gesellschaft in Cooperatives. In: Tuunanen M et al (eds) New development in the theory of networks, contributions to management science. Springer-Verlag, Berlin Heidelberg, pp 339-352

Nilsson J, Kihlén A, Norell L (2009) Are traditional cooperatives an endangered species? About shrinking satisfaction, involvement and trust. Int Food Agribusiness Manag Rev 12(4):103-123

Nilsson J, Ollila P (2009) Strategies and structures in the European dairy co-operative industry. J Co-operative Stud 42(2):14-23

Nilsson J, Svendsen GLH, Svendsen GT (2012) Are large and complex agricultural cooperatives losing their social capital? Agribusiness 28(2):187-204

Nooteboom B (2007) Social capital, institutions and trust. Rev Soc Econ 65:29-53

Ollila, P., Nilsson, J. and Hess, S. (2013). Member behavior within internationalized agricultural cooperatives. Paper for the 6th international conference on economics and Management of Networks (EMNet), held at the university Ibn Zohr, Agadir, Morocco, November 21-23, 2013

Ollila, P., Nilsson, J., and von Brömssen, C. (2011). Changing member loyalty in producer cooperatives. Paper for the 5th international conference on economics and Management of Networks (EMNet), held in Limassol, Cyprus, on December 1-3, 2011 
Österberg P, Nilsson J (2009) Members' perception of their participation in the governance of cooperatives: the key to trust and commitment in agricultural cooperatives. Agribusiness 25:181-197

Paldam M, Svendsen GT (2000) An essay on social capital: looking for the fire behind the smoke. Eur J Polit Econ 16:339-366

Payne GT, Moore CB, Griffis SE, Autry CW (2011) Multilevel challenges and opportunities in social capital research. J Manag 37(2):491-520

Pearson AW, Carr JC, Shaw JC (2008) Toward a theory of familiness: a social capital perspective. Entrepreneurship Theory Pract 32(6):949-969

Peng X, Hendrikse GWJ, Deng W (2016) Communication and innovation in cooperatives. J Knowl Econ:126

Pennerstorfer D, Weiss CR (2013) Product quality in the Agri-food chain: do cooperatives offer high-quality wine? Eur Rev Agric Econ 40(1):1-20

Peterson HC, Anderson BL (1996) Cooperative strategy: theory and practice. Agribusiness 12(4):371-383

Podolny JM, Baron JN (1997) Resources and relationships: social networks and mobility in the workplace. Am Sociol Rev 62(5):673-693

Putnam RD (1993) Making democracy work: civic traditions in modern Italy. Princeton University Press, Princeton

Røkholt, P.O. (1999). Strengths and weaknesses of the co-operative form: a matter of perspective and opinion. Paper presented at the ICA international research conference, Quebec, august 1999

Sabatini F (2014) Do cooperative enterprises create social trust? Small Bus Econ 42:621-641

Shaffer JD (1987) Thinking about farmers' cooperatives, contracts, and economic coordination. ACS Service report no. 18, U.S. Department of Agriculture, Washington, D.C.

Shapira R (1999) Loss of communal sustainability: the kibbutz shift from high-trust to low-trust culture. J Rural Coop 27(1):55-68

Smith K, Mitchell T, Summer C (1985) Top level management priorities in different stages of the organizational life cycle. Acad Manag J 28(4):799-820

Sparrowe R, Liden R, Wayne S, Kramer M (2001) Social networks and the performance of individuals and groups. Academic Manag J 44:316-325

Spear R (2000) The co-operative advantage. Annals Publ Cooperative Econ 71(4):507-524

Søgaard V (1994) Farmers, cooperatives, new food products. Mapp, Aarhus School of Business

Sykuta ME, Cook ML (2001) A new institutional economics approach to contracts and cooperatives. Am J Agric Econ 83(5):1273-1279

Trechter DD, King RP, Walsh L (2002) Using communications to influence member commitment in cooperatives. J Cooperatives 17:14-32

Tsai W, Ghoshal S (1998) Social capital and value creation: the role of intrafirm networks. Acad Manag J 41: $464-476$

Uzzi BD (1996) The sources and consequences of embeddedness for economic performance of organizations. Am Sociol Rev 61:674-698

Uzzi BD (1997) Social structure and competition in interfirm networks: the paradox of embeddedness. Adm Sci Q 42(1):36-67

Valentinov V (2004) Toward a social capital theory of cooperative organisation. J Cooperative Stud 37(3):520

Walker G, Kogut B, Shan W (1997) Social capital, structural holes, and the formation of an industry network. Organ Sci 8(2):109-125

Wambugu, S.N., Okello, J.J. and Nyikal, R.A., (2009). Effect of social capital on performance of smallholder producer organizations: the case of groundnut growers in Western Kenya. Contributed Paper prepared for presentation at the International Association of Agricultural Economists Conference, Beijing, China, August 16-22, 2009

Wu W (2008) Dimensions of social capital and firm competitiveness improvement: the mediating role of information sharing. J Manag Stud 45(1):122-146

Publisher's note Springer Nature remains neutral with regard to jurisdictional claims in published maps and institutional affiliations. 